\title{
O TUBO GÁSTRICO ISOPERISTÁLTICO NO TRATAMENTO PALIATIVO DO CÂNCER DO ESÔFAGO
}

\author{
ISOPERISTALTIC GASTRIC TUBE IN THE PALLIATIVE TREATMENT \\ OF ESOPHAGUS CANCER
}

\author{
Carlos Alberto Marcovechio Fonseca ${ }^{1}$ \\ Josias de Andrade Sobrinho, TCBC \\ Alexandre Pesciotto ${ }^{1}$ \\ Abrão Rapoport, TCBC-SP ${ }^{1}$
}

\begin{abstract}
RESUMO: Objetivo: Avaliar os resultados da derivação esofagogástrica no câncer avançado do esôfago. Método: Foram estudados de forma retrospectiva 24 pacientes com carcinoma epidermóide de esôfago nos estádios III $(66,66 \%)$ e IV $(33,34 \%)$, submetidos à derivação esofagogástrica através da construção do tubo gástrico isoperistáltico da grande curvatura pela técnica de Postlethwait. Resultados: Quanto à morbidade e mortalidade, os pacientes de média etária de 41,8 anos e linfócitos acima de $1.500 / \mathrm{mm}^{3}$ demonstraram taxas de complicações pós-operatórias inferiores àqueles com média de 54,09 anos. A fístula da anastomose, embora seja considerada comum (15 casos - 62,50\%), apresentou evolução benigna e ocluiu espontaneamente em 14 casos. Não houve qualquer tipo de complicação cirúrgica pós-operatória em cinco casos $(20,83 \%)$, o tempo médio cirúrgico foi de 285,77 minutos, e a mortalidade operatória de sete casos $(29,17 \%)$. A sobrevida foi 4,19 meses. Conclusões: Em vista da ocorrência de complicações, que determinam altas taxas de morbidade e mortalidade, o tubo gástrico isoperistáltico é um método de tratamento cirúrgico que deve ser dirigido a pacientes selecionados, em especial àqueles com número alto de linfócitos e idade mais baixa.
\end{abstract}

Descritores: Neoplasia esofagiana; Tubo gástrico isoperistáltico; Tratamento paliativo.

\section{INTRODUÇÃO}

O câncer do esôfago é a sexta neoplasia mais comum $^{1}$ e o carcinoma espinocelular apresenta uma prevalência mundial de 3 a 19:100.000 habitantes². Seu tratamento constitui-se em um grande desafio ${ }^{3}$. O diagnóstico da doença é freqüentemente tardio com predomínio de pacientes nos estádios $I I I$ e $I V$, quando a cura é impossível ${ }^{4}$. Estima-se que, em nosso país, aproximadamente 8.941 novos casos de câncer de esôfago foram diagnosticados no ano 2000 segundo o INCA/Ministério da Saúde 5 .

As populações de nível socioeconômico baixo ${ }^{6}$ possuem maior propensão para desenvolver câncer de esôfago, e a alimentação pode exercer uma participação muito importante na gênese desses tumores, cujo risco relativo de incidência é 17 vezes maior entre os consumidores de bebidas alcoólicas.
O diagnóstico do câncer de esôfago geralmente é tardio, porque a disfagia só ocorre quando mais de $60 \%$ da circunferência do órgão está infiltrada pelo tumor, e sua luz é reduzida para menos de $12 \mathrm{~mm}$ de diâmetro ${ }^{7}$. Em metanálise de 83.783 pacientes com carcinoma epidermóide de esôfago, num total de 122 publicações, registrou-se que de cada 100 pacientes, $58 \%$ foram candidatos à cirurgia e só $39 \%$ foram submetidos à ressecção do esôfago, com $18 \%$ vivos após um ano e $4 \%$ após cinco $\operatorname{anos}^{8}$. A complicação mais freqüente foi a fístula traqueoesofágica $(4,94 \% \text { a } 15 \%)^{9}$.

As cirurgias paliativas consistem em desviar o trânsito alimentar do esôfago, melhorando a qualidade de vida do paciente, além do que, o fato de poder alimentar-se por via oral já determina uma melhora psicológica, vista a intolerância dos estomas ${ }^{10}$.

O objetivo deste estudo foi analisar os resultados do tubo gástrico isoperistáltico no tratamento cirúrgico palia-

\section{Cirurgião do Complexo Hospitalar Heliópolis, São Paulo}

Recebido em 02/07/2001

Aceito para publicação em 28/05/2002

Trabalho realizado no Complexo Hospitalar Heliópolis, São Paulo-SP. 
tivo dos portadores de neoplasia avançada de esôfago, enfocando a sua morbidade, mortalidade e sobrevida.

\section{MÉTODO}

Foram estudados retrospectivamente 24 pacientes com carcinoma epidermóide avançado do esôfago, estádios III e IV (T4)da classificação TNM (UICC-União Internacional Contra o Câncer $)^{11}$ de 1998, tratados de forma paliativa no período de novembro de 1993 a dezembro de 2000. A maioria dos pacientes foi do sexo masculino $(91,70 \%)$, com um discreto predomínio da raça branca $(59,26 \%)$. A idade média foi de 51,85 anos, 23 pacientes eram tabagistas $(95,84 \%)$ e $22(91,67 \%)$ etilistas, com hábitos concomitantes de $86,96 \%$.

Na admissão, os pacientes apresentaram-se com sintomatologia por um período que variou de um a oito meses (média $=3,73$ ), sendo a disfagia e perda de peso as queixas mais freqüentes (Tabela 1) e a maioria dos pacientes apresentava tumores localizados no terço médio do esôfago torácico $(73,1 \%)$, cuja extensão variava de 3 a $9 \mathrm{~cm}$ (média $=5,8 \mathrm{~cm}$ ).

Tabela 1

Distribuição dos pacientes de acordo com a sintomatologia

\begin{tabular}{l|c|rr}
\hline Variável & Categorias & \multicolumn{2}{|c}{ Número $(\%)$} \\
\hline Disfagia & Não & 4 & $(16,66)$ \\
& Sim & 20 & $(83,34)$ \\
Perda de peso & Não & 3 & $(12,50)$ \\
& Sim & 21 & $(87,50)$ \\
Odinofagia & Não & 20 & $(83,34)$ \\
& Sim & 4 & $(16,66)$ \\
Regurgitação & Não & 20 & $(83,34)$ \\
& Sim & 4 & $(16,66)$ \\
Tosse & Não & 22 & $(91,67)$ \\
& Sim & 2 & $(8,33)$ \\
Melena & Não & 22 & $(91,67)$ \\
& Sim & 2 & $(8,33)$ \\
Rouquidão & Não & 22 & $(91,67)$ \\
& Sim & 2 & $(8,33)$ \\
Hematêmese & Não & 23 & $(95,84)$ \\
& Sim & 1 & $(4,16)$ \\
Outras & Não & 23 & $(95,84)$ \\
& Sim & 1 & $(4,16)$ \\
\hline
\end{tabular}

À broncoscopia, observou-se que 11 pacientes $(45,84 \%)$ apresentavam abaulamento traqueoesofágico, cinco $(20,84 \%)$ fístula traqueoesofágica e dois $(8,34 \%)$ laringite. Cinco pacientes $(20,84 \%)$ apresentavam grau de desnutrição leve $16(66,66 \%)$ desnutrição moderada e três $(12,50 \%)$ grau intenso de desnutrição.
Todos os pacientes foram operados utilizando tubo gástrico isoperistáltico pela técnica de Postlethwait modificada $^{12-13}$.

Os critérios de inclusão foram pacientes com carcinoma epidermóide avançado irressecável do esôfago, localizado em segmento torácico superior, médio ou inferior, com presença de fístula esofagotraqueal e ou brônquica com radioterapia prévia.

A avaliação da disfagia ${ }^{14}$ foi em grau zero (ausência de disfagia), grau um (disfagia para alimentos sólidos normais), grau dois (disfagia para uma dieta pastosa), grau três (disfagia para líquidos), grau quatro (disfagia completa).

A avaliação nutricional foi feita através da contagem de linfócitos e dosagem de albumina, e pelo índice de massa corpórea (IMC).

A análise estatística incluiu os métodos:

- estatística descritiva;

- teste exato de Fisher, para verificar a associação entre as variáveis categóricas;

- teste t de Student para amostras independentes, para comparação das médias das variáveis quantitativas;

- análise de sobrevida pelo método de Kaplan-Meier.

Para todos os testes, os níveis de significância foi estabelecido com $\mathrm{a}=5 \%$.

$\mathrm{O}$ ato cirúrgico era iniciado pela laparotomia mediana desde o apêndice xifóide até $3 \mathrm{~cm}$ abaixo da cicatriz umbilical, contornando-a pela esquerda, expondo completamente o esôfago abdominal mediante abertura do folheto peritoneal, e procedia-se à dissecção digital do esôfago torácico, mobilizando-o do saco pericárdico e dos recessos pleurais bilaterais, com secção da musculatura do anel hiatal em direção ao apêndice xifóide.

A grande curvatura gástrica era individualizada, preservando-se a arcada da artéria gastroepiplóica direita. Iniciava-se a construção do tubo gástrico do fundo para o antro gástrico, após a ligadura dos vasos breves e da artéria gastroepiplóica esquerda, liberando-se amplamente todo o fundo gástrico. Esta manobra permitia seccionar a grande curvatura gástrica a partir do fundo ${ }^{12}$, utilizando o grampeador linear cortante, construindo desse modo o tubo gástrico pela grande curvatura até $3 \mathrm{~cm}$ próximos ao piloro. $\mathrm{O}$ referido tubo isoperistáltico, nutrido pela artéria gastroepiplóica direita, era formado para ter no mínimo $3 \mathrm{~cm}$ de diâmetro, com um comprimento médio de $30 \mathrm{~cm}$ de extensão (Figuras 1, 2, 3). Quando se precisou de uma extensão maior do comprimento do tubo gástrico foi feita a manobra de Kocher para facilitar a ascensão do tubo gástrico da grande curvatura à região cervical, transposta através de um túnel retroesternal obtido pela dissecção deste espaço, entre a incisão cervical à esquerda e a abdominal.

Ao mesmo tempo em que a equipe trabalhava na confecção do tempo abdominal uma outra trabalhava em nível cervical com uma incisão de oito a dez centímetros de extensão, no bordo interno do músculo esternocleidomastóideo até a fúrcula external. 
Incisava-se a pele e o músculo platisma e seccionava-se todos os músculos pré-tireoideanos e afastava-se a glândula tireóide medialmente e o músculo esternocleidomastóideo esquerdo. O esôfago cervical era dissecado, evitando traumatizar o nervo laríngeo recorrente que deve ser reconhecido e preservado no sulco traqueoesofágico.

O esôfago cervical dissecado com amplidão permitia a secção o mais distal possível, após pontos de reparo no esôfago proximal com algodão 000 transfixando toda a parede do coto distal esofágico.

O coto proximal do esôfago era anastomosado ao tubo gástrico da grande curvatura por via retroesternal, término-terminal com pontos separados em dois planos. O primeiro plano era realizado com o fio sintético de ácido poliglicólico 000 e o segundo adventício-muscular e seromuscular com fio de algodão 000.

\section{RESULTADOS}

Houve melhora da disfagia em 16 casos $(66,66 \%)$ e um caso evoluiu com estenose da anastomose, não ocorrendo em nenhum dos pacientes necrose do tubo gástrico ou deiscência na área de sutura do estômago remanescente.

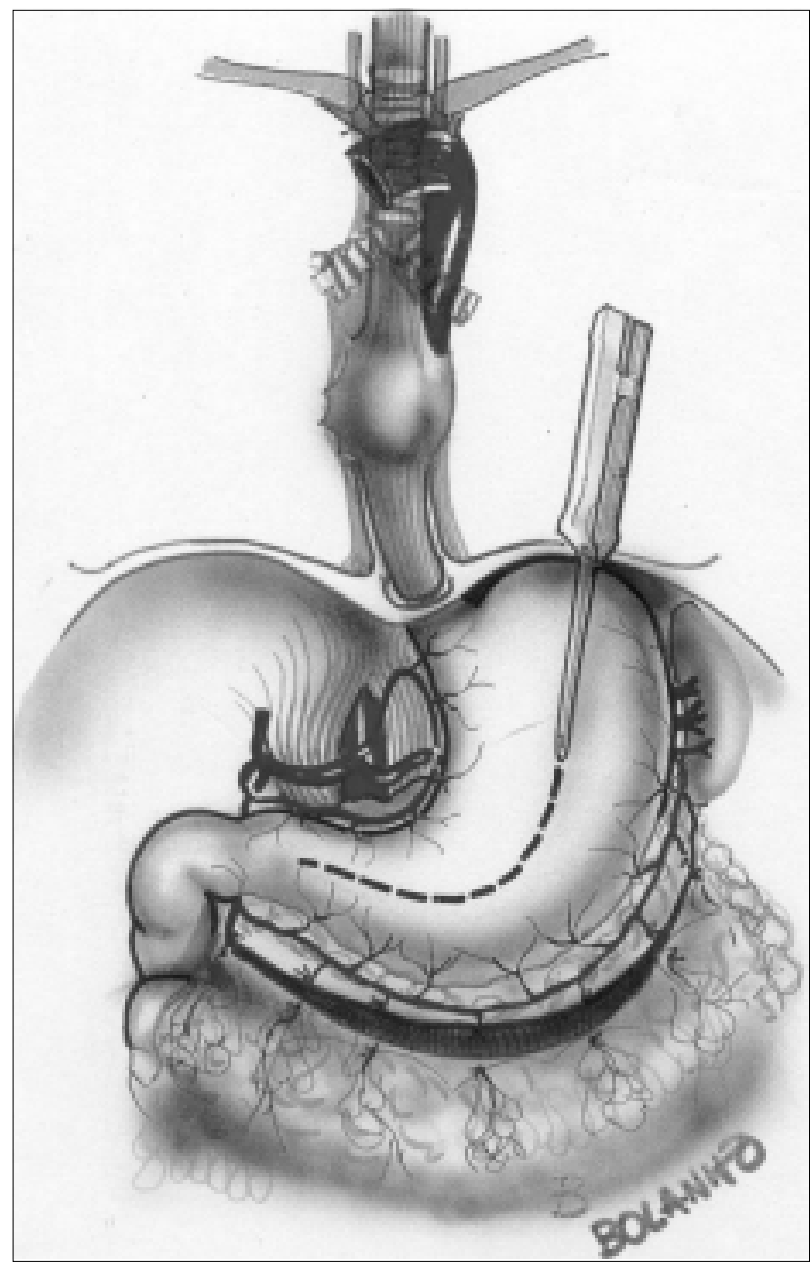

Figura 1. Início da construção do tubo gástrico, do fundo para o antro, após ligadura dos vasos breves.

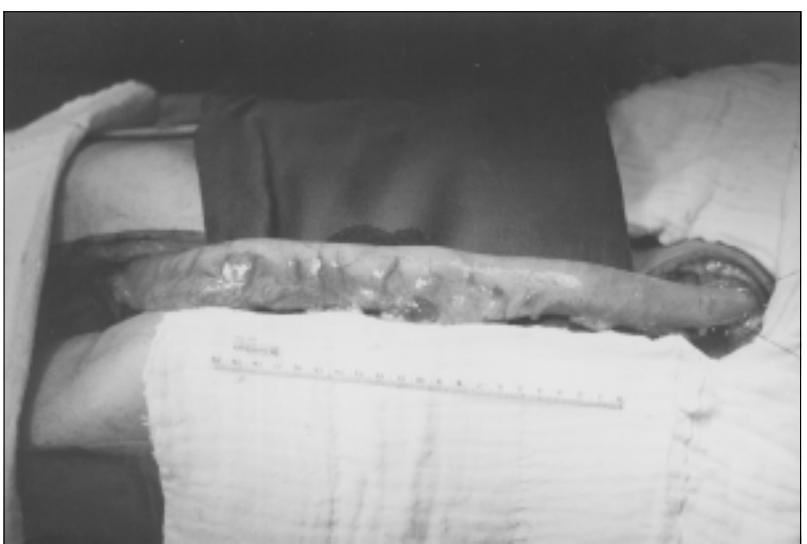

Figura 2. Aspecto final da construção do tubo gástrico.

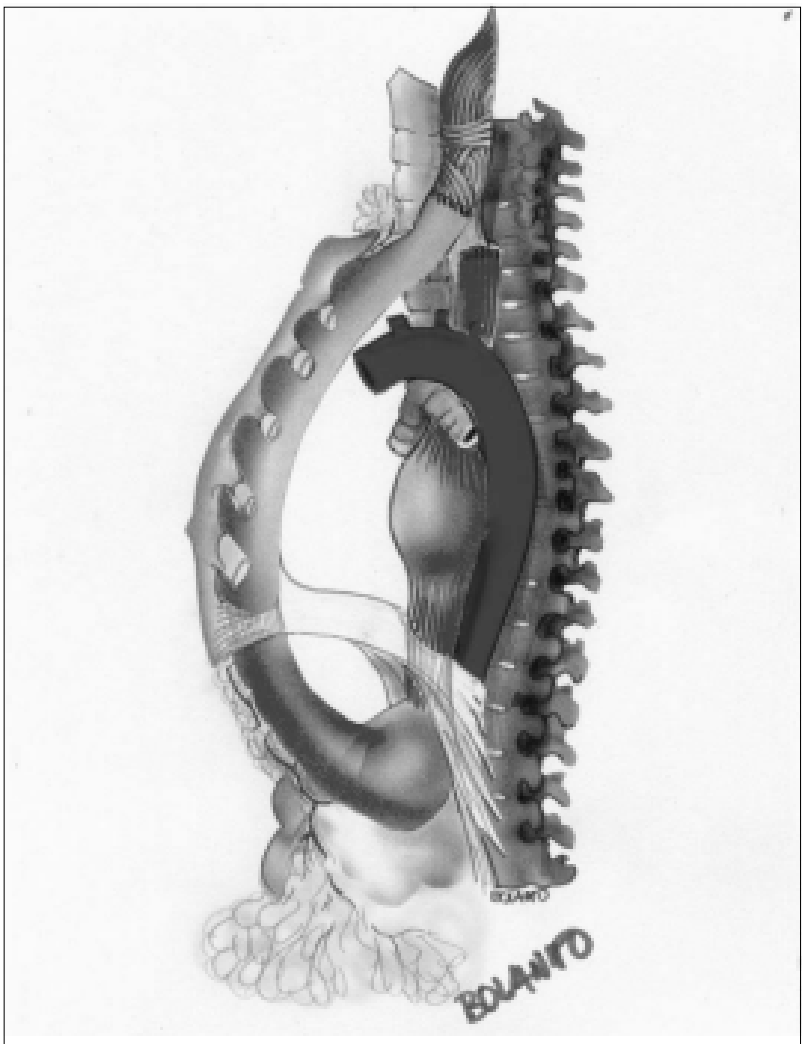

Figura 3. Aspecto final do tubo gástrico retroesternal, anastomosado ao esôfago proximal na região cervical.

As complicações pós-operatórias (Tabela 2) ocorreram em $79,17 \%$, sendo a mais freqüente a fístula cervical $(62,50 \%)$, seguida de insuficiência respiratória $(12,50 \%)$ e choque cardiogênico $(12,50 \%)$, não havendo deiscência da parede abdominal.

Dos nossos 24 casos, $46 \%$ dos operados faleceram após três meses, como se deduz após a plotação no Gráfico 1.

Observou-se diferença estatisticamente significante $(p<0,004)$ entre a média de idade dos pacientes com com- 
Tabela 2

Distribuição dos pacientes, segundo complicações pós-operatórias

\begin{tabular}{lcc}
\hline Variável & Categoria & Número (\%) \\
\hline Fístula cervical & Não & $9(37,50)$ \\
& Sim & $15(62,50)$ \\
Estenose da anastomose & Não & $23(95,83)$ \\
& Sim & $1(4,17)$ \\
Hematoma cervical & Não & $23(95,83)$ \\
& Sim & $1(4,17)$ \\
Insuficiência respiratória & Não & $21(87,50)$ \\
& Sim & $3(12,50)$ \\
Choque cardiogênico & Não & $21(87,50)$ \\
& Sim & $3(12,50)$ \\
Outras & Não & $23(95,83)$ \\
& Sim & $1(4,17)$ \\
\hline
\end{tabular}

A taxa de sobrevida global, após a cirurgia, em seis meses e um ano foi $54,0 \%$ e $10,8 \%$, respectivamente. O tempo médio de sobrevida foi 125,8 dias (4,19 meses), variando de um dia a 523 dias (17 meses) (Gráfico 1), sendo que aproximadamente $46 \%$ dos operados faleceram após três meses do ato cirúrgico.

\section{DISCUSSÃo}

A principal queixa dos pacientes com câncer avançado de esôfago é a disfagia que afeta o estado nutricional e ocorre aproximadamente um ano após o diagnóstico da lesão primária ${ }^{15}$. Em nossa casuística, todos os pacientes com câncer de esôfago procuraram atendimento médico tardiamente nos estádios III e IV. Considerado o alto custo das próteses, seus altos índices de morbimortalidade e o não alcance do objetivo que é a alimentação plena com alimentos sólidos, optamos pela alternativa cirúrgica paliativa na fase avançada da doença.

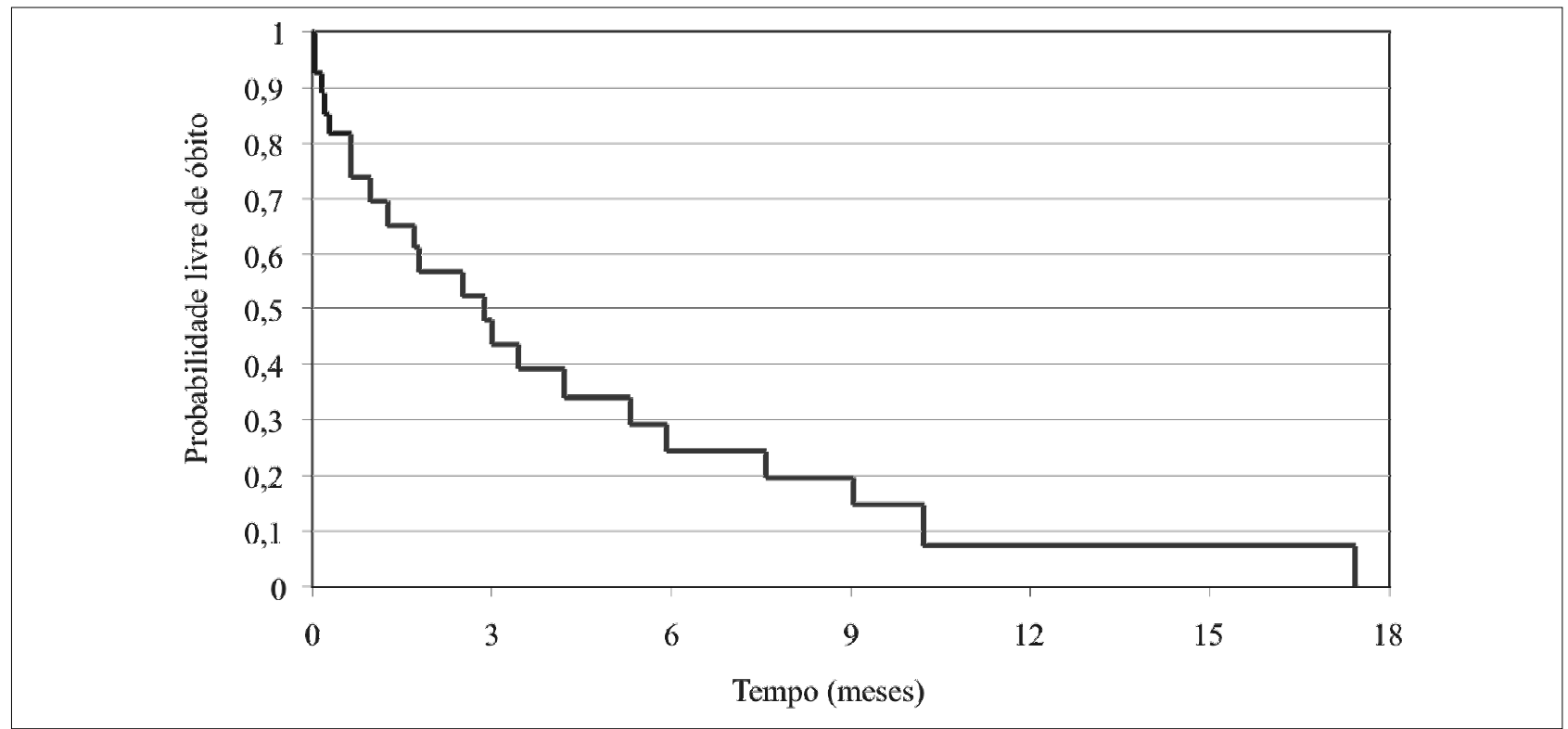

Gráfico 1. Curva de Kaplan-Meier.

plicações pós-operatórias (média $=54,09$ anos) e os que não as apresentaram (média $=41,8$ anos) $(\mathrm{p}=0,004)$, demonstrando que os pacientes mais jovens têm menores complicações pós-operatórias, além do número de linfócitos (média $=2.176,80)(\mathrm{p}=0,015)$ e dos leucócitos (média $=6.760,0)(\mathrm{p}=0,008)$ e da enzima AST (média $=$ 19,40) ( $\mathrm{p}=0,0020)$, conforme dados da Tabela 3.

O tempo cirúrgico variou de 180 a 420 minutos (média $=285,77)$, sendo a mortalidade operatória de $29,17 \%$ (7 pacientes), considerando o pós-operatório até 30 dias depois da cirurgia. Dentre os sete óbitos, três $(12,50 \%)$ tiveram como causa insuficiência respiratória por broncopneumonia, três $(12,50 \%)$ choque cardiogênico e um $(4,16 \%)$ choque séptico.
A transposição do tubo gástrico para reconstrução do trânsito alimentar possui grande aceitação, pois o estômago é um órgão bem vascularizado, que permite a construção de um tubo que pode ser transposto à região cervical. Apesar disto, esta técnica em pacientes em condições precárias leva a um alto índice de morbimortalidade ${ }^{16}$.

A construção do tubo gástrico apresenta sobre o estômago inteiro vantagens adicionais como: a eliminação de áreas de irrigação menos favorecidas (fundo gástrico e a pequena curvatura), formação e volume semelhantes ao esôfago normal e, sobretudo, a possibilidade de serem feitos tubos de extensão que com facilidade atingem a região cervical $^{17}$. Com essa técnica o esôfago distal mantém-se pérvio, evitando acúmulo das secreções esofágicas e a reali- 
Tabela 3

Média e desvio-padrão de idade e resultados de exames laboratoriais, segundo complicações pós-operatórias

\begin{tabular}{|c|c|c|c|}
\hline \multirow[b]{2}{*}{ Variável } & \multicolumn{2}{|c|}{ Complicações pós-operatórias } & \multirow[b]{2}{*}{$P$} \\
\hline & $\begin{array}{c}N a \tilde{o} o \\
\text { Média }(D P)\end{array}$ & $\stackrel{\text { Sim }}{\text { Média }(D P)}$ & \\
\hline Anos & 41,80 & $(7,27)$ & 0,004 \\
\hline Albumina (g/dl) & $(0,77)$ & $(0,66)$ & 0,492 \\
\hline Bilirrubina direta (mg/dl) & $(0,20)$ & $(0,90)$ & 0,910 \\
\hline Bilirrubina indireta (mg/dl) & $(0,10)$ & $(0,70)$ & 0,910 \\
\hline Bilirrubina total (mg/dl) & $(0,20)$ & $(1,40)$ & 0,850 \\
\hline Creatinina (mg/dl) & $(0,25)$ & $(0,48)$ & 0,950 \\
\hline Gama-GT (U/L) & $(160,9)$ & $(40,90)$ & 0,850 \\
\hline Hemoglobina $(\mathrm{g} / \mathrm{dl})$ & 12,96 & $(1,83)$ & 0,731 \\
\hline Hematócrito (\%) & 39,72 & $(5,37)$ & 0,595 \\
\hline Leucócitos $\left(\mathrm{mm}^{3}\right)$ & $6.760,0 \quad(1096,81)$ & $9.836,82(3023,83)$ & 0,008 \\
\hline Linfócitos (nº absoluto/mm³) & $2.176,80 \quad(637,16)$ & $1.304,95 \quad(660,48)$ & 0,015 \\
\hline Peso (kg) & $(10,47)$ & $(6,55)$ & 0,684 \\
\hline Proteína (g/dl) & $(0,50)$ & $(0,70)$ & 0,910 \\
\hline Tempo de atividade de protrombina (s) & $(14,40)$ & $(16,75)$ & 0,737 \\
\hline AST (U/L) & $(3,80)$ & $(18,10)$ & 0,020 \\
\hline ALT (U/L) & 27,00 & $(43,10)$ & 0,925 \\
\hline Uréia (mg/dl) & 20,40 & $(28,48)$ & 0,092 \\
\hline
\end{tabular}

zação de uma anastomose adicional esofagojejunal ${ }^{18}$. Há possibilidade de reconstrução do trânsito esofágico através de dois tipos de tubos gástricos ${ }^{19,20}$, que passaram a ser denominados de acordo com o sentido do peristaltismo do estômago: tubo gástrico anisoperistáltico, cuja extremidade livre era do antro piloro nutrido pela artéria gastroepiplóica esquerda, e o tubo gástrico isoperistáltico nutrido pela artéria gastroepiplóica direita e cuja extremidade livre situa-se na transição corpo/fundo gástrico.

A grande vantagem do tubo gástrico isoperistáltico é permitir a restauração adequada da deglutição.

O tubo gástrico anisoperistáltico no presente estudo não foi realizado porque quase sempre deve ser feita a esplenectomia, e a mucosa antral, constantemente estimulada pela passagem de alimento ou secreção alcalina, é responsável pela ocorrência de maior freqüência de úlce$\mathrm{ra}^{17,21}$.

Os pacientes de nosso estudo eram fumantes e etilistas em sua maioria, com doenças pulmonares prévias acentuadas, indicadores de um alto risco cirúrgico para a morbidade de $79,17 \%$, equivalente à literatura ${ }^{12}-35$.

As fístulas da anastomose cervical são complicações da técnica. Postlethwait ${ }^{13}$ atribuiu à ausência da serosa do esôfago, o decréscimo do fluxo sangüíneo na porção terminal do tubo, falha técnica e tensão excessiva da anasto- mose. A tração do esôfago no momento da deglutição causaria tensão da anastomose e, como conseqüência, isquemia transitória local. $\mathrm{O}$ tubo gástrico conduzido à região cervical, pela via retroesternal, favoreceria a compressão da anastomose no nível cervical ${ }^{18}$. O ângulo crítico na anastomose pode ser um ponto fraco da técnica.

A colonização elevada do esôfago, na presença de obstrução, aumentaria a incidência da fístula que foi de $62,50 \%$ enquanto na literatura variou de $0 \%$ a $59,1 \%$ 1,6,12,13,17,24-28 .

Em nosso estudo, a maioria das fístulas fechou espontaneamente em 15 dias $^{16}$. Em um caso de fístula da anastomose esôfago-tubo gástrico, de alto débito, houve necessidade de reoperação com resultado satisfatório.

Quanto à disfagia, observamos melhora em 16 dos 24 casos $(66,66 \%)$, enquanto na literatura são citadas cifras de até $88 \%$ de sucesso ${ }^{12,18,29,30,35}$. Para a sobrevida, a média foi de 5,2 meses, valores usuais nas diferentes escolas cirúrgicas $1,13,17,24,31$.

A explicação para a baixa taxa de sobrevida seria a pior condição clínica de nossos pacientes. O baixo nível sérico de albumina menor que $3,5 \mathrm{~g} / 100 \mathrm{ml}$, a pequena população de linfócitos menor que $1.200 / \mathrm{mm}^{3}$, e a história de uma perda de peso importante pré-operatória são indicadores de um mau estado nutricional, e justificam a alta taxa de morbidade. 
Os resultados mostraram uma diferença significativa $\mathrm{p}<0,05$ (Tabela 3 ) entre a média de idade dos pacientes com complicações pós-operatórias (média de 54,2 anos) e os que não as tiveram (média de 41,8 anos) ( $\mathrm{p}=0,004$ ), demonstrando que os pacientes mais jovens apresentam menos complicações.

O número de linfócitos foi considerado fator prognóstico estatisticamente significante (Tabela 3). Pode-se inferir que a baixa taxa de linfócitos (abaixo de 1.300/ $\mathrm{mm}^{3}$ ) aumenta o risco de complicações pós-operatórias.

Também foi estatisticamente significante $(p<0,020)$ a relação entre os níveis séricos da AST e as complicações pós-operatórias (Tabela 3). Para melhor explicar estes dados, temos que considerar que a AST, enzima mitocondrial, está amplamente distribuída nos tecidos humanos, principalmente no fígado, na musculatura esquelética e nos rins. Pequenas quantidades são encontradas no pâncreas, baço e pulmões, e diferem da ALT por serem menos específicas em doenças do fígado, elevando-se em torno de $30 \%$ a $75 \%$ nos alcoólatras. Vale ressaltar que as complicações que ocorreram no pós-operatório, como insuficiência respiratória, choque cardiogênico, complicações infecciosas e uso de vários medicamentos, podem explicar a maior elevação da enzima AST no grupo que apresentou um maior número de complicações pós-operatórias, uma vez que o etilismo não foi fator discriminante entre os grupos estudados.

Nossos resultados demonstram que $85,18 \%$ dos pacientes tinham passado de etilismo e $92,59 \%$ de tabagis- mo e aproximadamente $86,96 \%$ possuíam os dois hábitos com doenças pulmonares prévias acentuadas o que seria indicador de um alto risco cirúrgico para a morbidade e mortalidade ${ }^{12}$.

A morbidade com a derivação pós-tubo gástrico isoperistáltico varia de $60 \%{ }^{16}$ a $77 \%{ }^{12}$. Em nossos casos, a morbidade encontrada foi $79,17 \%$ (19 dos 24 casos).

Embora os bons resultados quanto ao alívio permanente da disfagia sejam reconhecidos, como a prevenção de complicações decorrentes de aspiração e a possibilidade de tratar o tumor com radioterapia pósoperatória, as dificuldades inerentes à técnica operatória em pacientes em más condições gerais fazem com que esta cirurgia esteja associada a uma taxa elevada de complicações e letalidade. Os resultados da literatura são bastante heterogêneos, com a letalidade oscilando entre $0 \%$ e $43 \% 1,12,13,23-25,28,31-35$.

O tubo gástrico da grande curvatura é cirurgia que apresenta alta morbimortalidade, mas que permite aos sobreviventes um convívio social próximo do normal, retardando, mesmo que por pouco tempo, a evolução natural da doença e uma melhora acentuada do estado geral.

Em síntese, a reconstrução do trânsito esofágico através do tubo gástrico isoperistáltico constitui-se em uma opção terapêutica para pacientes nos estádios clínicos III e IV, com idade abaixo de 41,8 anos e número de linfócitos acima de $1.500 \mathrm{~mm}^{3}$, com o intuito de diminuir a disfagia e excluir a fístula traqueoesofágica.

\begin{abstract}
Background: Evaluation of esophageal gastric derivation with isoperistaltic gastric tube in advanced esophageal cancer. Method: Twenty-four patients presenting esophageal squamous cell carcinoma classified as stage III $(66.66 \%)$ and IV $(33.34 \%)$, were submitted to an esophagus gastric derivation through the construction of an isoperistaltic gastric tube of the large flexure, using the Postlethwait's technique. Results: Patients with a mean age of 41.8 years and lymphocytes above 1,500/ $\mathrm{mm}^{3}$, showed less postoperative disorders than those with a mean age of 54.09 years. Anastomotic fistula, although considered normal in 15 cases (62.50\%), presented a benign evolution and spontaneously healed in 14 cases. No postoperative complications were observed in 5 cases $(20.83 \%)$ and mean surgical time was 285.77 minutes. Survival rate was 4.19 months. Conclusions: In spite of high morbidity and mortality rates the isoperistaltic tube is a surgical procedure that must be suggested to well selected cases, specially those with a great rate of lymphocytes, low mean age and in cases where anastomosis fistula has a benign evolution.
\end{abstract}

Keywords: Esophageal neoplasia; Isoperistaltic gastric tube; Palliative treatment.

\title{
REFERÊNCIAS
}

1. Muñoz N. Epidemiological aspects of oesophageal câncer. Endoscopy 1993, 25:609-612.

2. Moura EGH, Maluf Filho F, Sakai P. Câncer avançado do esôfago. In: Sakai P. Tratado de endoscopia digestiva: diagnóstico e terapêutica. São Paulo, Atheneu 1999, 151-162.

3. Ferreira EAB, Ferreira FO. Câncer do esôfago. In: Moraes M.F. ed. Princípios da cirurgia oncológica. São Paulo, Atheneu 1996, 133-150.
4. Knyrim K, Wagner HJ, Bethge N, Keymling M, Vakil N. A controlled trial of an expansile metal stent for palliation of esophageal obstruction due to inoperable cancer. N Engl J Med 1993, 329:1302-1307.

5. Ministério da Saúde. Estimativas da incidência e mortalidade por câncer no Brasil, 2000. Rio de Janeiro, INCA 2000.

6. Mirra AP. Epidemiologia do câncer de esôfago. ABCD Qrq Brás Cir Diag 1988, 3: 37-41. 
7. Demeester TR, Barlow AP. Surgery and current management for cancer of the esophagus and cardia: part I. Curr Probl Surg 1988, 25:477-534.

8. Earlam R, Cunha-Melo JR. Oesophageal squamous cell carcinoma: I. a critical review of surgery. Br J Surg 1980, 67:381-390.

9. Martini N, Goodner JT, D'angio GJ, Beattie Jr. EJ. Tracheoesophageal fistula due to cancer. J Thorac Cardiovasc Surg 1970, 59:319-324.

10. Cecconello I, Zilberstein B, Domene CE, Meniconi MT, Pinotti HW. Tratamento paliativo do câncer do esôfago. ABCD Arq Bras Cir Dig 1990, 5(Supl 1):17-20.

11. Sobin LH , Wittekind CH. eds. TNM classificação dos tumores malignos. 5 ed. Trad. De Instituto Nacional de Câncer. Rio de Janeiro, INCA 1998,59-62: Esofago.

12. Alcantara PSM, Spencer Netto FAC, Silva Jr JF, Soares LA, Pollara WM, Bevilacqua RG. Gastro-esophageal isoperistaltic bypass in the palliation of irresectable thoracic esophageal cancer. Int Surg 1997, 82:249 -253.

13. Postlethwait RW. Technique for isoperistaltic gastric tube for esophageal bypass. Ann Surg 1979, 189:673-676.

14. Mellow MH, Pinkas H. Endoscopic laser therapy for malignancies affecting the esophagus and gastroesophageal junction: analysis of technical and functional efficacy. Arch Intern Med 1985, 145:1443-1446.

15. Tinoco RC, Tinoco LA, Figueira SE, Cavichini QN, Brum AV Anderson PAV, Couto FC. Tratamento cirúrgico do carcinoma de esôfago. Rev Bras Cir 1982, 72:297-307.

16. Corsi PR, Campos T, Pinto MCC, Viana AT, Frimm CE, Gagliardi D. Tubo gástrico isoperistáltico no tratamento paliativo do carcinoma do esôfago. An Paul Med Cir 1999, 126:106-110.

17. Speranzini MB, Fujimura I, Pires PWA, Mittelstaedt WEM, Deutsch CR, Bourroul Filho RC, Quintas ML, Rodrigues Jr A. Esofagoplastia com tubo gástrico isoperistáltico em derivação no tratamento do câncer do esôfago torácico: estudo de 13 casos. Rev Assoc Med Bras 1989, 35:91-98.

18. Orringer MB. Substernal gastric bypass of the excluded esophagus: results of an ill-advised operation. Surgery $1984,96: 467-470$.

19. Carter BN, Abbott AO, Hanlon R. An experimental study of tubes made from the greater curvature of the stomach. J Thorac Surg 1942, 11:494-515.

20. Schettini ST. Esofagoplastia por tubos gástricos em crianças: bases morfológicas e técnicas. São Paulo, 1981 [Tese Mestrado - Escola Paulista de Medicina].

21. Sugimachi K, Yalta A, Ueo H, Natsuda Y, Inokuchi K. A safer and more reliable operative technique for esophageal reconstruction using a gastric tube. Am J Surg 1980, 140:471-474.

22. Lázaro da Silva A, Lira AR, Melo JRC, Tanure JC. Câncer do esôfago. Rev Goiania Med 1984, 30:29-42.

23. Brandalise NA, Andreollo NA, Leonardi LS, Callejas Neto $\mathrm{F}$, Nagase Y. Utilização do tubo gástrico na reconstrução do trânsito digestivo em neoplasias do esôfago e junção esofagogástrica. Rev Col Bras Cir 1985, $12: 152-155$

24. Cantero R, Torres AJ, Hernando F, Gallego J, Lezana A, Suarez A, Balibrea JL. Palliative treatment of esophageal cancer: self-expanding metal stents versus postlethwait technique. Hepato-Gastroenterol 1999, 46:971-976.
25. Meniconi MTM. Estudo prospectivo da aplicação do tubo gástrico de grande curvatura, isoperistáltico no tratamento da neoplasia avançada de esôfago - análise de 50 casos. São Paulo, 1997. [Tese Doutorado - Faculdade de Medicina da Universidade de São Paulo].

26. Meunier B, Spiliopoulos Y, Stasik C, Lakéhal M, Malledant Y, Launois B. Retrosternal bypass operation for unresectable squamous cell cancer of the esophagus. Ann Thorac Surg 1996, 62:373-377.

27. Orringer MB. Esophageal carcinoma: what price palliation? [editorial]. Ann Thorac Surg 1983b, 36:377-379.

28. Wong J, Lam KH, Wei WI, Ong GB. Results of the Kirschner operation. World J Surg 1981, 5:547-552.

29. Abe S, Tachibana M, Shimokawa T, Shiraishi M, Nakamura T. Surgical treatment of advanced carcinoma of the esophagus. Surg Gynecol Obstet 1989, 168:115-119.

30. Mannell A, Becker PJ, Nissenbaum M. Bypass surgery for unresectable oesophageal cancer: early and late results in 124 cases. Br J Surg 1988, 75:283-286.

31. Akiyama H \& Hiyama M. A simple esophageal bypass operation by the high gastric division. Surgery 1974 , 75:674-681.

32. Conlan AA, Nicolaou N, Hammond CA, Pool R, Nobrega C, Mistry BD. Retrosternal gastric bypass for inoperable esophageal cancer: a report of 71 patients. Ann Thorac Surg 1983, 36:396-401.

33. Mannell A. Presternal gastric bypass for unresectable carcinoma of the thoracic oesophagus: a preliminary report. Am J Surg 1980, 67:522-527.

34. Paricio PP, Marcilla JAG, Haro LM, Escandell MAO, Escrig C. Results of surgical treatment of epidermoid carcinoma of the thoracic esophagus. Surg Gynecol Obstet 1993, 177:398-404.

35. Robinson JC, Isa SS, Spees EK, Rogers EL, Gadacz TR. Substernal gastric bypass for palliation of esophageal carcinoma: rationale and technique. Surgery 1982, 91:305-311.

Endereço para correspondência:

Prof. Dr. Abrão Rapoport

Pça. Amadeu Amaral, 47 - cj. 82 - Paraíso

01327-010 — São Paulo-SP

E-mail: cpgcp.hosphel@attglobal.net 